\title{
Immunization coverage in Ethiopia among 12-23 month children: systematic review and meta-analysis.
}

Tahir Yousuf Nour ( $\nabla$ daahir571@gmail.com )

Jigjiga University https://orcid.org/0000-0001-6406-5821

Alinoor Mohamed Farah1

Jigjiga University

Omer Moeline Ali

Jigjiga University

Kalkidan Hassen Abate

Jimma University

\section{Systematic Review}

Keywords: immunization coverage, systematic review, pastoral, semi-pastoral, meta-analysis, Ethiopia

Posted Date: February 26th, 2020

DOI: https://doi.org/10.21203/rs.2.24598/v1

License: () (1) This work is licensed under a Creative Commons Attribution 4.0 International License. Read Full License 


\section{Abstract}

Background: Immunization is cost-effective public health interventions strategies of the decade which under go long and careful process to ensure vaccine safeness before it reaches to the target children, it averts nearly three million mortality annually and immunization coverage is very low comparing all plans at national and regional. The aim of this systematic review and meta-analysis is to assess pooled immunization coverage in Ethiopia.

Method: systematic search was done from PubMed, Google Scholar, Embase, and Hinari, SCOPUS, WHO's Institutional Repository for Information Sharing (IRIS), African Journals Online databases, grey literature and reviewing reference lists of already identified articles. Checklist from the Joanna Briggs Institute was used to assess risk of bias of the included study while heterogeneity was assessed using $\mathrm{I}^{2}$. Funnel plot were used to assess publication bias. Metaanalysis using random effect model was used to estimate the pooled prevalence of immunization among $12-23$ month children using STATA 13 software.

Result: twenty eight articles were included in the meta-analysis with, a total sample size of 20,048 12-23 months children. The pooled prevalence of immunization among 12-23 month children in Ethiopia was found $47 \%$ (95\%, $\mathrm{Cl}$ : 46.0, 47.0). Subgroup analysis by region indicated the lowest proportion of immunized children in Afar region, $21 \%(95 \%, \mathrm{Cl}$ : 18.0, 24.0) and the highest in Amhara region, 89\% $(95 \%, \mathrm{Cl}: 85.0,92.0)$.

Conclusion: Nearly $50 \%$ of $12-23$ month children were fully vaccinated for this systematic review and meta-analysis but coverage is still low with clear disparity among regions. Mobile and outreach immunization sites should be planned for hard to reach area of pastoral and semi-pastoral regions. Immunization service should be integrated to private for profit and not for profit health facilities which cover $11 \%$ of health service coverage in Ethiopia.

\section{Background}

Immunization is one of the cost-effective public health interventions that are used to eliminate life threatening childhood illness like diphtheria, pertussis, tetanus, hepatitis virus, measles, mumps, pneumonia, polio virus and rotavirus. Globally, it decreases $2-3$ million mortality yearly, whereas vaccine preventable diseases (VPD) accounts worldwide over 2 million under five deaths annually majority of them from sub-Sahara African countries [1-3].

According to World Health Organization (WHO) children are considered fully immunized when they received one dose of Bacillus Calmette Guerin (BCG), three doses of DPT, three doses of polio vaccines, and one dose of measles vaccination by the age of $9-12$ months $[4,5]$

2017 WHO report revealed that, 116.2 million infants (85\%) received third dose of DPT, internationally, only 123 (63\%) of 194 countries achieved three doses of DPT coverage $\geq 90 \%$. vaccine uptake is dramatically increased but new and underused vaccines which makes 19.9 million under one year children are not received DPT 3 vaccine, 12.4 million did not complete three doses, 13.7 million did not receive any DTP dose ("left out") and 6.2 million are dropped [6-8].

WHO 2018 reported that That 19.4 million infants are completed DPT3 where 13.5 million didn't received initial dose of vaccine due to lack of access to immunization services, while Ethiopia and other nine countries hold 11.7 million of 19.4 under and unimmunized children which accounts $60 \%$ [9]

Over 6 million under five children died worldwide in 2013, which several deaths are attributed by VPD. Government improved service utilization by training of 38,000 health extension workers with 15000 health posts integrated community case management in 2010; endorsing SDG \#3 targets 3.2 aimed preventable deaths of newborns and under-five children by 2030. Despite availability of cost effective and affordable interventions to decrease under-five mortality there is alarming of VPD like: diarrhea, measles and pneumonia which annually cause 3, 37000 cases of measles, pneumonia, and diarrhea [5, 10-15]

There are contributing factors that significantly associate with vaccine coverage in Ethiopia, those are rural residence, employer, female household head, primary and secondary school, antenatal care follow up, delivering health facility, Level of maternal education, good knowledge on immunization, short distance to health facility, having four or more family size can increase vaccine coverage in contrary fear of side effect, low wealth status, being too busy, hearing rumor about vaccination were predictors and barrier of fully vaccination[6, 16-19]

Although private for profit and not for profit health facilities accounts for about $11 \%$ of health service coverage in Ethiopia all most all of them are not providing routine immunization if they provide routine immunization with free cost may contribute a lot to the coverage[20]

Understanding the extent of vaccine coverage and its associated factors is important for designing strategies that can reduce the burden of vaccine preventable diseases. There is no review and meta-analysis conducted in Ethiopia on immunization coverage among 12-23 month old. Therefore, aims of this meta-analysis was to pool and synthesize recent evidence on the prevalence of vaccine coverage among 12-23 months children using small fragmented regional studied to pool and form national result to consolidate available data and determine current prevalence of vaccine coverage in Ethiopia.

\section{Methods}

\section{Search strategy and appraisal of studies}

All published studies conducted in Ethiopia reporting the fully vaccinated or immunization coverage from September 2009 to 2019 were included. The search was limited to English language, human and cross sectional studies. This study was conducted according to the Preferred Reporting Items of Systematic Reviews and Meta-Analysis Protocols (PRISMA-P) checklist guidelines [21]. The electronic databases searched were PubMed, Google Scholar, Embase, and Hinari, SCOPUS, WHO's Institutional Repository for Information Sharing (IRIS), and African Journals Online databases. In addition to that, articles were also searched through a review of the grey literature available on local university shelves, and institutional repositories, and by reviewing the reference lists of already identified articles. The key terms used for the database searches were connected by bloomean operators in our search below Medical Subject Headings (MeSH terms): “Epidemiologic" OR "Child” OR "Children” AND “Coverage, Vaccination" OR "Vaccination coverages" OR "Immunization Coverage "OR 
Coverage, Immunization" OR "coverages, Immunization" OR "Immunization coverage" AND "Ethiopia". The search was Publication date from 2009/01/01 to 2019/11/01.

\section{Inclusion and exclusion criteria}

All English-language, full-text articles for studies conducted in Ethiopia, published from 2009 to September 2019, in peer-reviewed journals or found in the grey literature were eligible for inclusion. Case definition were adopted from WHO EPI Fully immunized is defined when they have received one dose of Bacillus Calmette Guerin (BCG), three doses of DPT, three doses of polio vaccines, and one dose of measles vaccination by the age of 9-12 months [4, 22]. All studies that reported the vaccination coverage in children 12-23 month were eligible for inclusion. Studies that did not report specific outcomes for immunization quantitatively, age $>12-23$ month and study design other than cross-sectional study design were excluded.

\section{Data abstraction procedure}

Two authors (TY and AM) independently extracted data using Joanna Briggs Institute data extraction tool for cross-sectional study design, any disagreement was resolved through discussion and consensus reached through third person. Outcome data extraction format contain author, publication year, region, sample size, study design, response rate, prevalence rate with $95 \%$ confidence interval. Retrieved articles were evaluated based on their title, objective, and methodology. At this stage, irrelevant articles were excluded and the full text of the remainder articles was reviewed for inclusion criteria. Articles that fulfilled the prior criteria were used as a source of data for the final analysis

\section{The database search results were exported}

Duplicate articles were removed using EndNote software (version X7; Thomson Reuters, New York, NY). Two independent reviewers critically appraised each individual article using the using quality assessment checklist for prevalence studies before analysis which was included representation, sampling, random selection, non-response rate, data collection, case definition, reliability and validity of study tool, method of data collection, prevalence,numerator and denominator lastly quality summary [23]. It was categorized as having low risk of bias "yes" high risk of bias "no" if the score is 8-10 we consider it as having "low risk of bias" 6-7 score "moderate risk of bias" 0-5 score "high risk of bias"(Table 1).

Any disagreement between reviewers was resolved through discussion and reaching consensus including a third reviewer. The average of two independent reviewer's quality scores was used to determine whether the articles should be included. Articles with methodological errors or incomplete reporting of results those with no full text were excluded from the final analysis.

\section{Outcome measurements and statistical analysis}

The main aim of this review was to assess pooled prevalence of immunization coverage among children 12-23 month in Ethiopia. It was measured as the number of children who took one dose BCG, 3 doses of DTP, 3 doses of OPV and one dose of measles vaccine divided by the total number of children in a study multiplied by 100 .

Information on the studies characteristics such as publication year, study region, study design, sample size, non-respondent and immunization coverage were extracted from each study using a Microsoft Excel spreadsheet template. Then, data were exported to Stata (version 13; Stata Corp, College Station, TX) for further analysis. A random effect model was used to estimate pooled prevalence of fully vaccinated children with $95 \%$ confidence interval (Cl) in Ethiopia. Funnel plot asymmetry was used to check for publication bias (Figure 3 ). Heterogeneity between studies was assessed using 1 -squared $\left(\mathrm{I}^{2}\right)$ statistics and the cutoffs of $25,50,75 \%$ was used to declare heterogeneity as low, moderate and high respectively[24] also subgroup analysis was conducted to detect prevalence of immunization coverage and heterogeneity among regional states of the country.

\section{Operational definitions}

Pastoralist and semi-pastoralist:- means communities, located in Benishangul Gumuz, Gambella, Oromia, Somali, and Southern Nations, Nationalities and Peoples' regions[25].

Fully vaccinated: when children receive one dose of Bacillus Calmette Guerin (BCG), three doses of DPT, three doses of polio vaccines, and one dose of measles vaccination by the age of $9-12$ months $[4,5]$

\section{Results}

In the first step of our search, 363 articles were retrieved about immunization coverage among children aged 12-23 month using different electronic databases were searched: like PubMed, Google Scholar, Embase, and Hinari, Web of Science, SCOPUS, WHO's Institutional Repository for Information Sharing (IRIS), and African Journals Online databases. 22 articles were excluded due to duplication, from remaining 341 articles 308 articles were excluded not related to the topic, not done in Ethiopia and study design. Only 35 full text articles were accessed and assessed for their eligibility based on inclusion criteria. Finally 28 articles were eligible and included in this meta-analysis (figure 1). 


\section{Characteristics of included studies}

All retained twenty eight studies in this systematic review and meta-analysis conducted in Ethiopia all of them were cross sectional; twenty five of them were conducted from eight regional states and three national survey, a total sample size of 20,048 of (aged 12-23 months) old children included. The minimum sample size was 173[26] and maximum sample size was 2004[27] Nin (32.1\%) of studies were from Amhara region [28-36], six (21.4\%) from South Nation Nationality and People's region[18, 26, 37-40], four (14.3\%) from Oromia region[41-44], were three (10.7\%) survey nationwide [27, 45, 46], two (7.1\%) from pastoral and semi-pastoral area of the country [25, 47], lastly one (3.6\%) from Somali state [48] and one (3.6\%) from Tigrai regional states[49] All studies were published in peer review journals that fulfills WHO/UNICEF case definition for maternal recall, immunization card and scare were used.

An estimated over all pooled prevalence of immunization coverage among 12-23 month children in Ethiopia was $47 \%$ (95\% confidence interval (Cl: 46/0,047.0)) (figure 2). The lowest

Proportion included studies was $21 \%(95 \%, \mathrm{Cl}: 18.0,24.0)[50]$ and the highest $89 \%(95 \%, \mathrm{Cl}: 85.0,92.0)[31]$. The I-square test shown that there was no heterogeneity among included studies $\left(I^{2}=0.00, p\right.$-value < 0.005). Studies with largest weight were EDHS 2016[27], EDHS 2011[51] and Mebrahtom and Birhane [52] 9.99,9.62,7.65 respectively. Those with smallest weight were Facha wolde [40], Porth et al [37] and Gualu and Dillie [31] with respective weight of $1.05,1.16$ and 1.44 .

Heterogeneity test showed that there was no significant publication bias among studies after we run funnel plot as shown $\left(I^{2}=0.000, p\right.$-value $\left.<0.005\right)($ Figure 2).

\section{Subgroup analysis}

We have conducted subgroup analysis based on regional states of the country, Tigrei region had highest prevalence of immunization coverage $12-23$ month children $77 \%$ (95\% Cl: 74.0,81.0) followed by Amhara region 71\% (95\% Cl: 70.0,72.0), SNNP 60\% (95\% Cl: 58.0,62.0), Oromia region 41\% (95\% Cl: 41.0,42.0), Somali region, $37 \%(95 \% \mathrm{Cl}: 33.0,41.0)$ and A far region had the smallest immunization coverage in Ethiopia $12 \%(95 \% \mathrm{Cl}$ : 10.0,13.0). In subgroup analysis Amhara region had the highest weight 26.06 the possible reason may be high number of study done and included on that area and lowest weight was Somali region 2.90 (Figure.3).

\section{Publication bias}

In the present study there was no publication bias because funnel plot visual presentation showed that a symmetric distribution of studies conducted this meta-analysis as illustrated below (Figure.4)

\section{Discussion}

Immunization is cost-effective public health intervention that prevents VPD and their complications like amputation of limbs, paralysis, hearing loss, convulsions, brain damage, hepatocellular carcinoma as well as death of children it is also have had greatest impact of decreasing health care cost and inequality among global population.

Ethiopian government still struggling to achieve it is target of immunization coverage despite implementing different strategies and approaches. In this systematic review and meta-analysis, we assessed pooled prevalence of immunization coverage among 12-23 month children in Ethiopia. To our knowledge, this meta-analysis is first its kind in Ethiopia for immunization coverage.

Over all pooled prevalence of immunization coverage among children was $47.0 \%$ (95\% Cl: 46.0, 47.1). These prevalence lower than the WHO 2018 factsheet report of $86 \%$ [9] it is also lower than DHS reports of Lower and Middle Income Countries (LMIC), such as 67.2\% Kenya[53], 62.5\% Cameroon[54], 77.0\% Ghana[55], 75.3\% Tanzania[56], 62\% India[57], 70.0\% Philippines[58],82\% Bangladesh[59], 76.0\% Zimbabwe [60] and 61.0\% South Africa [61]. it is lower than administrative /HMIS/ of fully vaccinated children which is $88 \%$ and government target of health sector transformation plan-IV (HSTP) which was $93 \%$ [62].

But this meta-analysis is in line with other DHS reports that are nearly similar to this study with prevalence of 49.1\%Madagascar[63], 55.8\% Uganda[64].

In contrary this meta-analysis is higher than Nigerian DHS report and meta-analysis pooled prevalence of immunization coverage among $12-23$ month children $31.0 \%$ Nigeria[65] and $34.4 \%(\mathrm{Cl}: 27.0,41.9)$ respectively [66].

Immunization is a proven tool for controlling and eliminating life-threatening infectious disease which prevent 2-3 million under-five deaths annually. Provision of measles vaccine can support cognitive gain, school-grade attainment, decrease malnutrition, economic consequence after childhood and also prevent severe pneumonia and diarrhea $[67,68]$

We found regional variation for immunization coverage among 12-23 month children lowest prevalence was observed from Afar region $12.0 \%$ (95\% Cl: 10.0 , 13.0) were evidences showed that access to health facilities is very low, $82.12 \%$ of population resides in rural and pastoralist due to that and other reasons under five mortality is highest in Afar region comparing other eight regionals states which is (125 per 1000 live birth) high percent of death can be prevented simply providing immunization services children living hard-to-reach area [27, 69]. Somali region is next to Afar region where immunization coverage is low and $37.0 \%$ (95\% Cl: $33.0 \%, 41.0 \%)$. 
Pastoral and Semi-pastoral region share same socio-demographic, socio-cultural and socio-economic characteristics special strategies and approaches are needed to answer those pastoralist regions concern which can increase access and utilization of health service particularly immunization service in those area.

The possible reason could be socio-demographic, socio-economic and cultural characteristics of the community, access to the health facilities and utilization of immunization services are very low to pastoral and Semi-pastoral area of the countries. This systematic review and meta-analysis shown low immunization coverage is public health problem in Ethiopia due to recurrent episodes of vaccine preventable disease to those low immunization coverage regions.

The highest was Amhara region 71\% (95\% Cl: 70.1, 72.0). (Table 4) which is mostly Agrarian region and population are settled the other reason may be, educational status of the community is relatively good comparing to other region, also road access to the health facilities, other infrastructure like electricity coverage that is directly helpful to routine immunization also health service utilization is good based on evidences among different regional states of Ethiopia.

Although Trends of immunization coverage in Ethiopia is slightly increased for $24 \%$ to 43 from $2011-2019$ respectively[27, 45, 51] but still there are challenges which need special consideration particularly pastoral and semi-pastoral regions that deserve to give special consideration when routine immunization programs are planning.

This review was done extensive search and more than two reviewer involved to minimize all possible risk of bias. But there are some limitation of this review we only reviewed cross-sectional studies which are prone for confounding, the number of studies distributed among region was not equal, Only English language, some articles were published emerging journals, and numbers of studies were very few all the above mentioned points may affect the overall result.

\section{Conclusion}

Study found that pooled prevalence of immunization coverage among 12-23 month children were very low comparing both international and national immunization coverage. Therefore, we strongly recommend government should strength mobile and outreach immunization site for hard to reach of pastoral and semi-pastoral areas, integrating both human and animal health posts, Integrate immunization service both private for profit and not for profit health facilities because they account $11 \%$ of health coverage of the country which hardly provide free immunization service, also future research should be considered for all states of the country that may reveal more about prevalence of immunization coverage.

\section{Abbreviations}

BCG Bacillus Calmette Guerin

Cl Confidence Interval

DHS Demographic Health Survey

DPT Diphtheria Pertussis Tetanus

EDHS Ethiopia Demographic Health Survey

EPI Expanded Program of Immunization

HMIS Health Management Information System

IRIS Institutional Repository for Information Sharing

JBI Joanna Briggs Institute

LMIC Low and Middle Income Countries

PRISMA Preferred Reporting Items of Systematic Reviews

And Meta-Analysis

SDG Sustainable Development Goals

VPD Vaccine Preventable Diseases

WHO World Health organization

\section{Declarations}

\section{Acknowledgment}

The authors would like to thank Collage of Medicine and Health Science staffs for their support the authors would also like to express appreciation to DHS forum for their guidance in data analysis.

\section{Authors' contributions}


TY conceived the study, study selection, preparation of protocol, searching strategy for literature, participated data analyzes, interpretation and manuscript preparation. AM and OM involved in developing protocol, searching strategy, critical appraisal, data extraction and draft of manuscript, $\mathrm{KH}$ prepared and supported, final draft of manuscript. All authors (TY, AM, OM and KH) involved all steps read and approved final draft of manuscript.

\section{Funding}

This meta-analysis has no any funding agencies in government or non-government organization.

\section{Availability of data and materials}

The dataset for this study is available from the corresponding author on reasonable request.

Ethical approval and Consent of participants

Not applicable

\section{Consent for publication}

Not applicable

\section{Competing interests}

The author declares there was no competing of interest

\section{Author's detail}

*Department of Public Health, Collage of Medicine and Health science, P.O.Box 1020 Jigjiga, Ethiopia.

**Department of Population and Family Health, Jimma University, Ethiopia.

\section{References}

1.Wondwossen, L., et al., Advances in the control of vaccine preventable diseases in Ethiopia. 2017, African Field Epidemiology Network.

2.Organization, W. H., RSV vaccine research and development technology roadmap: priority activities for development, testing, licensure and global use of RSV vaccines, with a specific focus on the medical need for young children in low-and middle-income countries. 2017, World Health Organization.

3.Banteyerga, H., Ethiopia's health extension program: improving health through community involvement. MEDICC review, 2011. 13(3): p. 46-49.

4.Mekonnen, A. G., A.D. Bayleyegn, and E. T. Ayele, Immunization coverage of 12-23 months old children and its associated factors in Minjar-Shenkora district, Ethiopia: a community-based study. BMC Pediatrics, 2019. 19(1): p. 198.

5.Animaw, W., et al., Expanded program of immunization coverage and associated factors among children age 12-23 months in Arba Minch town and Zuria District, Southern Ethiopia, 2013. BMC Public Health, 2014. 14(1): p. 464.

6.Tamirat, K. S. and M. M. Sisay, Full immunization coverage and its associated factors among children aged 12-23 months in Ethiopia: further analysis from the 2016 Ethiopia demographic and health survey. BMC Public Health, 2019. 19(1): p. 1019.

7.Hailu, S., et al., Low immunization coverage in Wonago district, southern Ethiopia: A community-based cross-sectional study. PloS one, 2019. 14(7): p. e0220144.

8.Jayaraman, S. P., et al., GBD 2015 Child Mortality Collaborators. Global, regional, national, and selected subnational levels of stillbirths, neonatal, infant, and under-5 mortality, 1980-2015: a systematic analysis for the Global Burden of Disease Study 2015. Lancet2016.

9.Organization, W. H., Expanded programme on Immunization (EPI) factsheet 2019: Indonesia. 2019.

10.Organization, W. H., Don't pollute my future! The impact of the environment on children's health. 2017, World Health Organization.

11.Miller, N. P., et al., Integrated community case management of childhood illness in Ethiopia: implementation strength and quality of care. The American journal of tropical medicine and hygiene, 2014. 91(2): p. 424-434.

12.Berhan, Y. and A. Berhan, Causes of maternal mortality in Ethiopia: a significant decline in abortion related death. Ethiopian journal of health sciences, 2014. 24: p. 15-28.

13.Lanata, C. F., et al., Global causes of diarrheal disease mortality in children< 5 years of age: a systematic review. PloS one, 2013. 8(9): p. e72788. 
14.Bilal, N. K., et al., Health extension workers in Ethiopia: improved access and coverage for the rural poor. Yes Africa Can: Success Stiroes from a Dynamic Continent, 2011: p. 433-443.

15.Shiffman, J., Generating political priority for maternal mortality reduction in 5 developing countries. American journal of public health, 2007. 97(5): p. 796803.

16.Girmay, A. and A. F. Dadi, Full Immunization Coverage and Associated Factors among Children Aged 12-23 Months in a Hard-to-Reach Areas of Ethiopia. Int J Pediatr, 2019. 2019: p. 1924941.

17.Boulton, M. L., et al., Vaccination timeliness among newborns and infants in Ethiopia. PLoS One, 2019. 14(2): p. e0212408.

18.Tefera, Y. A., et al., Predictors and Barriers to Full Vaccination among Children in Ethiopia. Vaccines (Basel), 2018. 6(2).

19.Okeibunor, J. C., et al., Polio eradication in the African Region on course despite public health emergencies. Vaccine, 2017. 35(9): p. 1202-1206.

20.World Health, O., WHO country cooperation strategy at a glance: Ethiopia. 2018, World Health Organization: Geneva.

21.Moher D, L. A., Tetzlaff J, Altman DG, The PRISMA Group (2009). Preferred Reporting Items for Systematic Reviews and Meta-Analyses: The PRISMA Statement.. PLoS Med e1000097.. 6(6).

22.Animaw, W., et al., Expanded program of immunization coverage and associated factors among children age 12-23 months in Arba Minch town and Zuria District, Southern Ethiopia, 2013. BMC Public Health, 2014. 14: p. 464.

23.Hoy, D., et al., Assessing risk of bias in prevalence studies: modification of an existing tool and evidence of interrater agreement. Journal of clinical epidemiology, 2012. 65(9): p. 934-939.

24.Huedo-Medina, T. B., et al., Assessing heterogeneity in meta-analysis: Q statistic or I $^{2}$ index? Psychological methods, 2006.11 (2): p. 193.

25.Kidanne, L., et al., Child vaccination timing, intervals and missed opportunities in pastoral and semi-pastoral areas in Ethiopia. Ethiopian Journal of Health Development, 2019. 33.

26.Fite, R. O. and L. D. Hailu, Immunization coverage of 12 to 23 months old children in Ethiopia. 2019.

27.CSA, I., Central statistical agency (CSA)[Ethiopia] and ICF. Ethiopia demographic and health survey, Addis Ababa, Ethiopia and Calverton, Maryland, USA, 2016.

28.Yismaw, A. E., et al., Incomplete childhood vaccination and associated factors among children aged 12-23 months in Gondar city administration, Northwest, Ethiopia 2018. BMC Res Notes, 2019. 12(1): p. 241.

29.Mekonnen, A. G., A.D. Bayleyegn, and E. T. Ayele, Immunization coverage of 12-23 months old children and its associated factors in Minjar-Shenkora district, Ethiopia: A community-based study. BMC Pediatrics, 2019. 19(1).

30.Tesfaye, T. D., W. A. Temesgen, and A. S. Kasa, Vaccination coverage and associated factors among children aged 12 - 23 months in Northwest Ethiopia. Hum Vaccin Immunother, 2018. 14(10): p. 2348-2354.

31.Gualu, T. and A. Dilie, Vaccination coverage and associated factors among children aged 12-23 months in debre markos town, amhara regional state, ethiopia. Advances in Public Health, 2017. 2017.

32.Lake, M., et al., Factors for Low Routine Immunization Performance; A Community Based Cross Sectional Study in Dessie Town, South Wollo Zone, Ethiopia, 2014. Advances in Applied Sciences, 2016. 1: p. 7-17.

33.Kassahun, M. B., G. A. Biks, and A. S. Teferra, Level of immunization coverage and associated factors among children aged 12-23 months in Lay Armachiho District, North Gondar Zone, Northwest Ethiopia: a community based cross sectional study. BMC Research Notes, 2015. 8(1).

34.Ebrahim, T. and W. Beyene, Childhood immunization coverage in tehulederie district, northeast of ethiopia: A community based cross sectional study. International Journal of Current Research, 2015. 7(9): p. 20234-20240.

35.Debie, A. and B. Taye, Assessment of fully vaccination coverage and associated factors among children aged 12-23 months in Mecha District, North West Ethiopia: A cross-sectional study. Sci J Public Health, 2014. 2(4): p. 342-8.

36.Animaw, W., et al., Expanded program of immunization coverage and associated factors among children age 12 - 23 months in Arba Minch town and Zuria District, Southern Ethiopia, 2013. BMC Public Health, 2014. 14(1).

37.Porth, J. M., et al., Childhood immunization in Ethiopia: Accuracy of maternal recall compared to vaccination cards. Vaccines, 2019. 7(2).

38. Hailu, S., et al., Low immunization coverage in Wonago district, southern Ethiopia: A community-based cross-sectional study. PLoS One, 2019. 14(7): p. e0220144. 
39.Meleko, A., M. Geremew, and F. Birhanu, Assessment of Child Immunization Coverage and Associated Factors with Full Vaccination among Children Aged 12-23 Months at Mizan Aman Town, Bench Maji Zone, Southwest Ethiopia. Int J Pediatr, 2017. 2017: p. 7976587.

40.Facha, W., Fully Vaccination Coverage and Associated Factors among Children Aged 12 to 23 Months in Arba Minch Zuriya Woreda, Southern Ethiopia. 41.Legesse, E. and W. Dechasa, An assessment of child immunization coverage and its determinants in Sinana District, Southeast Ethiopia. BMC Pediatrics, 2015. 15(1).

42.Wado, Y. D., M. F. Afework, and M. J. Hindin, Childhood vaccination in rural southwestern Ethiopia: the nexus with demographic factors and women's autonomy. The Pan African medical journal, 2014. 17: p. 9.

43.Mohammed, H. and A. Atomsa, Assessment of child immunization coverage and associated factors in Oromia regional state, eastern Ethiopia. Science, Technology and Arts Research Journal, 2013. 2(1): p. 36-41.

44.Etana, B. and W. Deressa, Factors associated with complete immunization coverage in children aged 12-23 months in Ambo Woreda, Central Ethiopia. BMC Public Health, 2012. 12(1).

45.Indicators, K., Mini Demographic and Health Survey. 2019.

46.Demographic, E., Health survey 2011 central statistical agency Addis Ababa. Ethiopia ICF International Calverton, Maryland, USA, 2012.

47.Tessema, F., et al., Child vaccination coverage and dropout rates in pastoral and semi-pastoral regions in Ethiopia: CORE Group Polio Project implementation areas. Ethiopian Journal of Health Development, 2019. 33.

48.Mohamud, A. N., et al., Immunization coverage of 12-23 months old children and associated factors in Jigjiga District, Somali National Regional State, Ethiopia. BMC Public Health, 2014. 14: p. 865.

49.Girmay, A. and A. F. Dadi, Full Immunization Coverage and Associated Factors among Children Aged 12-23 Months in a Hard-to-Reach Areas of Ethiopia. International Journal of Pediatrics, 2019. 2019.

50.Beyene, E. Z., et al., Factors associated with immunization coverage among children age 12-23 months: the case of Zone 3, Afar Regional State, Ethiopia. Ethiopian medical journal, 2013. 51 Supp/ 1: p. 41-50.

51.ICF, C., Central Statistical Agency [Ethiopia] and ICF International. Ethiopia Demographic and Health Survey, 2011.

52.Mebrahtom, S. and Y. Birhane, Magnitude and determinants of childhood vaccination among pastoral community in Amibara District, Afar Regional State, Ethiopia. Res J Med Sci Pub Health, 2013. 1(3): p. 22-35.

53.Demographic, K., Health Survey 2014: key indicators. Kenya National Bureau of Statistics (KNBS) and ICF Macro, 2014.

54.EDSM, V., Enquête démographique et de Santé au Mali 2012-2013. Disponible: cnom. sante. gov. ml/docs/FR286. pdf (accès le 06/04/2018 à 20H 18) P, 2013. 252: p. 290.

55.GHSGDPI, G. S. S., Ghana Demographic and Health Survey 2014. Key Indicators, 2015.

56.Demographic, T., Health Survey and Malaria Indicator Survey, 2015-2016. Dar es Salaam, United Republic of Tanzania, and Rockville MD, United States of America: Ministry of Health, Community Development, Gender, Elderly and Children (Dar es Salaam), Ministry of Health (Zanzibar), National Bureau of Statistics (Dar es Salaam), Office of the Chief Government Statistician (Zanzibar), ICF, 2016.

57.Sciences, I. I.f.P. and ICF, National Family Health Survey (NFHS-4), 2015-16: India. 2017, IIPS Mumbai.

58.Authority, P. S., Philippines National Demographic and Health Survey 2017: Key Indicators. Quezon City, Philippines, and Rockville, Maryland, 2018.

59.Research, N. I.o.P., et al., Bangladesh demographic and health survey. 2011: National Institute of Population Research and Training (NIPORT).

60.Agency, Z. N. S. and I. International, Zimbabwe demographic and health survey 2015. 2016, Zimbabwe National Statistics Agency (ZIMSTAT) ICF International Rockville....

61.National Department of Health, S. S. A., South African Medical Research Council, and ICF, South Africa Demographic and Health Survey 2016: key indicators. 2017, NDoH, Stats SA, SAMRC and ICF Pretoria, South Africa and Rockville, Maryland ....

62.Health, F. D. R.o.E. M.o., HSTP Health Sector Transformation Plan 2015/16-2019/20 (2008-2012 EFY). 2015, Federal Democratic Republic of Ethiopia Ministry of Health.

63.statistique, I.n.d.I. and I. Macro, Enquête démographique et de santé Madagascar, 2008-2009. 2010: Institut national de la statistique, Ministère de l'économie et de l'industrie.

64.Statistics, U. B.o. and ICF, Uganda demographic and health survey 2016: key indicators report. 2017, UBOS, and Rockville Maryland. 
65.Commission, N. P., and ICF International. Nigeria Demographic and Health Survey 2013. Abuja: National Population Commission and ICF International; 2014. 2018.

66.Adeloye, D., et al., Coverage and determinants of childhood immunization in Nigeria: a systematic review and meta-analysis. Vaccine, 2017. 35(22): $\mathrm{p}$. $2871-2881$.

67.Nandi, A., et al., Anthropometric, cognitive, and schooling benefits of measles vaccination: Longitudinal cohort analysis in Ethiopia, India, and Vietnam. Vaccine, 2019. 37(31): p. 4336-4343.

68.Bawankule, R., et al., Does Measles Vaccination Reduce the Risk of Acute Respiratory Infection (ARI) and Diarrhea in Children: A Multi-Country Study? PLoS One, 2017. 12(1): p. e0169713.

69.Woldemichael, A., et al., Inequalities in healthcare resources and outcomes threatening sustainable health development in Ethiopia: Panel data analysis. BMJ Open, 2019. 9(1).

70.Etana, B. and W. Deressa, Factors associated with complete immunization coverage in children aged 12-23 months in Ambo Woreda, Central Ethiopia. BMC Public Health, 2012. 12: p. 566.

71.Kassahun, M. B., G. A. Biks, and A. S. Teferra, Level of immunization coverage and associated factors among children aged 12-23 months in Lay Armachiho District, North Gondar Zone, Northwest Ethiopia: a community based cross sectional study. BMC Res Notes, 2015. 8: p. 239.

72.Legesse, E. and W. Dechasa, An assessment of child immunization coverage and its determinants in Sinana District, Southeast Ethiopia. BMC Pediatr, 2015. 15: p. 31.

73.Wado, Y. D., M. F. Afework, and M. J. Hindin, Childhood vaccination in rural southwestern Ethiopia: the nexus with demographic factors and women's autonomy. Pan Afr Med J, 2014. 17 Suppl 1: p. 9.

74.Beyene, T. J., et al., Determinants of health seeking behaviour following rabies exposure in Ethiopia. Zoonoses Public Health, 2018. 65(4): p. 443-453.

\section{Appendix}

Search Child or children AND Coverage, Vaccination OR Coverages, Vaccination OR Vaccination Coverages OR Immunization Coverage OR Coverage, Immunization OR Coverages, Immunization OR Immunization Coverages AND Ethiopia Filters: Free full text; Publication date from 2009/01/01 to 2019/12/31; Humans Sort by: [pubsolr12]

\section{Tables}

\section{Figures}


Table 1 Risk of bias assessment of eligible articles using the Hoy 2012 tool

\begin{tabular}{|c|c|c|c|c|c|c|c|c|c|c|}
\hline study & Representation & sampling & $\begin{array}{l}\text { Random } \\
\text { selection }\end{array}$ & $\begin{array}{l}\text { Non } \\
\text { response } \\
\text { rate }\end{array}$ & $\begin{array}{l}\text { Data } \\
\text { collection }\end{array}$ & $\begin{array}{l}\text { Case } \\
\text { definition }\end{array}$ & $\begin{array}{l}\text { Reliability } \\
\text { and } \\
\text { Validity } \\
\text { of study } \\
\text { tool }\end{array}$ & $\begin{array}{l}\text { Method } \\
\text { of Data } \\
\text { collection }\end{array}$ & prevalence & $\begin{array}{l}\text { Numeratos } \\
\text { and } \\
\text { Denomina }\end{array}$ \\
\hline $\begin{array}{l}\text { Animaw et } \\
\text { al[22] }\end{array}$ & High risk & Low risk & Low risk & Low risk & Low risk & Low risk & Low risk & Low risk & Low risk & Low risk \\
\hline $\begin{array}{l}\text { Etana and } \\
\text { Deressa[70] }\end{array}$ & High risk & Low risk & Low risk & Low risk & Low risk & Low risk & Low risk & Low risk & Low risk & Low risk \\
\hline $\begin{array}{l}\text { Gualu and } \\
\text { Dilie[31] }\end{array}$ & High risk & Low risk & Low risk & Low risk & Low risk & Low risk & Low risk & Low risk & Low risk & Low risk \\
\hline $\begin{array}{l}\text { Hailu et } \\
\text { al[38] }\end{array}$ & Low risk & Low risk & Low risk & Low risk & Low risk & Low risk & Low risk & Low risk & Low risk & Low risk \\
\hline $\begin{array}{l}\text { Girmay and } \\
\text { Dadi[16] }\end{array}$ & Low risk & Low risk & Low risk & Low risk & Low risk & Low risk & Low risk & Low risk & Low risk & Low risk \\
\hline $\begin{array}{l}\text { Kassahun et } \\
\text { al[71] }\end{array}$ & High risk & Low risk & Low risk & Low risk & Low risk & Low risk & Low risk & Low risk & Low risk & Low risk \\
\hline $\begin{array}{l}\text { Lake et } \\
\text { al[32] }\end{array}$ & High risk & High risk & Low risk & Low risk & High risk & Low risk & High risk & Low risk & Low risk & Low risk \\
\hline $\begin{array}{l}\text { Legesse and } \\
\text { Dechasa[72] }\end{array}$ & Low risk & Low risk & Low risk & Low risk & Low risk & Low risk & High risk & Low risk & Low risk & Low risk \\
\hline $\begin{array}{l}\text { Mekonnen et } \\
\text { al[4] }\end{array}$ & Low risk & Low risk & Low risk & Low risk & Low risk & Low risk & Low risk & Low risk & Low risk & Low risk \\
\hline $\begin{array}{l}\text { Meleko et } \\
\text { al[39] }\end{array}$ & High risk & Low risk & Low risk & Low risk & Low risk & Low risk & Low risk & Low risk & Low risk & Low risk \\
\hline $\begin{array}{l}\text { Mohammed } \\
\text { and } \\
\text { Atomsa } 43]\end{array}$ & High risk & Low risk & Low risk & Low risk & Low risk & Low risk & High risk & Low risk & Low risk & Low risk \\
\hline $\begin{array}{l}\text { Mohamud et } \\
\text { al[48] }\end{array}$ & Low risk & Low risk & Low risk & Low risk & Low risk & Low risk & High risk & Low risk & Low risk & Low risk \\
\hline $\begin{array}{l}\text { Tefera et } \\
\text { al[18] }\end{array}$ & High risk & Low risk & $\begin{array}{l}\text { High } \\
\text { risk }\end{array}$ & Low risk & Low risk & Low risk & High risk & Low risk & Low risk & Low risk \\
\hline $\begin{array}{l}\text { Fite and } \\
\text { Haili[26] }\end{array}$ & High risk & High risk & Low risk & Low risk & High risk & Low risk & High risk & Low risk & High risk & High risk \\
\hline $\begin{array}{l}\text { Tesfaye et } \\
\text { al[30] }\end{array}$ & Low risk & Low risk & Low risk & Low risk & Low risk & Low risk & High risk & Low risk & Low risk & Low risk \\
\hline $\begin{array}{l}\text { Wado et } \\
\text { al[73] }\end{array}$ & High risk & Low risk & Low risk & Low risk & Low risk & Low risk & High risk & Low risk & Low risk & Low risk \\
\hline $\begin{array}{l}\text { Yismaw et } \\
\text { al[28] }\end{array}$ & Low risk & Low risk & Low risk & Low risk & Low risk & Low risk & High risk & Low risk & Low risk & Low risk \\
\hline $\begin{array}{l}\text { Beyene et } \\
\text { al[74] }\end{array}$ & High risk & Low risk & Low risk & Low risk & High risk & Low risk & High risk & Low risk & Low risk & Low risk \\
\hline $\begin{array}{l}\text { Mebrahtom } \\
\text { and }\end{array}$ & High risk & Low risk & Low risk & Low risk & Low risk & Low risk & Low risk & Low risk & Low risk & Low risk \\
\hline $\begin{array}{l}\text { Birhane[52] } \\
\text { Debie and } \\
\text { Taye[35] }\end{array}$ & High risk & Low risk & Low risk & Low risk & Low risk & Low risk & High risk & Low risk & Low risk & Low risk \\
\hline $\begin{array}{l}\text { Facha } \\
\text { W [40] }\end{array}$ & High risk & Low risk & Low risk & Low risk & Low risk & Low risk & High risk & Low risk & Low risk & Low risk \\
\hline $\begin{array}{l}\text { Ebrahim and } \\
\text { Beyene[34] }\end{array}$ & High risk & Low risk & Low risk & Low risk & Low risk & Low risk & Low risk & Low risk & Low risk & Low risk \\
\hline $\begin{array}{l}\text { Tessema et } \\
\text { al [47] }\end{array}$ & High risk & Low risk & Low risk & Low risk & Low risk & Low risk & Low risk & Low risk & Low risk & Low risk \\
\hline $\begin{array}{l}\text { Kidane et } \\
\text { al[25] }\end{array}$ & High risk & Low risk & Low risk & Low risk & Low risk & Low risk & Low risk & Low risk & Low risk & Low risk \\
\hline $\begin{array}{l}\text { Porth et } \\
\text { al [37] }\end{array}$ & High risk & Low risk & $\begin{array}{l}\text { High } \\
\text { risk }\end{array}$ & Low risk & High risk & Low risk & High risk & Low risk & Low risk & Low risk \\
\hline EDHS [51] & Low risk & Low risk & Low risk & Low risk & Low risk & Low risk & Low risk & Low risk & Low risk & Low risk \\
\hline EDHS [27] & Low risk & Low risk & Low risk & Low risk & Low risk & Low risk & Low risk & Low risk & Low risk & Low risk \\
\hline EDHS [45] & Low risk & Low risk & Low risk & Low risk & Low risk & Low risk & Low risk & Low risk & Low risk & Low risk \\
\hline
\end{tabular}


Table 2: summary characteristics of included studies in meta-analysis of immunization coverage in Ethiopia, 2009 to 2019.

\begin{tabular}{|c|c|c|c|c|c|c|c|c|}
\hline Author & year & Region & study base & Event & $\mathrm{N}$ & $\begin{array}{l}\text { Response } \\
\text { rate }\end{array}$ & $\begin{array}{l}\text { Quality } \\
\text { score }\end{array}$ & $\begin{array}{l}\text { prevalence } \\
\text { with it is } 95 \% \\
\text { CI }\end{array}$ \\
\hline Animaw et al[22] & 2014 & Amhara & $\begin{array}{l}\text { community } \\
\text { based }\end{array}$ & 461 & 630 & $100 \%$ & 9 & $73 \%(70,76)$ \\
\hline Etana and Deressa[70] & 2012 & Oromia & $\begin{array}{l}\text { community } \\
\text { based }\end{array}$ & 193 & 536 & $100 \%$ & 9 & $36 \%(32,40)$ \\
\hline Gualu and Dilie[31] & 2017 & Amhara & $\begin{array}{l}\text { community } \\
\text { based }\end{array}$ & 256 & 288 & $96.80 \%$ & 9 & $89 \%(85,92)$ \\
\hline Hailu et al[38] & 2019 & SNNP & $\begin{array}{l}\text { community } \\
\text { based }\end{array}$ & 483 & 1116 & $82.70 \%$ & 10 & $43 \%(40,46)$ \\
\hline Girmay and Dadi[16] & 2019 & Tegrai & $\begin{array}{l}\text { community } \\
\text { based }\end{array}$ & 480 & 620 & $99.50 \%$ & 10 & $77 \%(74,81)$ \\
\hline Kassahun et al[71] & 2915 & Amhara & $\begin{array}{l}\text { community } \\
\text { based }\end{array}$ & 566 & 751 & $99.20 \%$ & 9 & $75 \%(72,78)$ \\
\hline Lake et al[32] & 2016 & Amhara & $\begin{array}{l}\text { community } \\
\text { based }\end{array}$ & 472 & 724 & $100 \%$ & 6 & $65 \%(62,69)$ \\
\hline Legesse and Dechasa[72] & 2015 & Oromia & $\begin{array}{l}\text { community } \\
\text { based }\end{array}$ & 393 & 519 & $98.50 \%$ & 9 & $76 \%(72,79)$ \\
\hline Mekonnen et al[4] & 2019 & Amhara & $\begin{array}{l}\text { community } \\
\text { based }\end{array}$ & 423 & 566 & $98.80 \%$ & 10 & $75 \%(71,78)$ \\
\hline Meleko et al[39] & 2017 & SNNP & $\begin{array}{l}\text { community } \\
\text { based }\end{array}$ & 295 & 322 & $100 \%$ & 9 & $92 \%(88,94)$ \\
\hline $\begin{array}{l}\text { Mohammed and } \\
\text { Atomsa[43] }\end{array}$ & 2013 & Oromia & $\begin{array}{l}\text { community } \\
\text { based }\end{array}$ & 155 & 685 & $98.70 \%$ & 8 & $23 \%(20,26)$ \\
\hline Mohamud et al[48] & 2014 & Somali & $\begin{array}{l}\text { community } \\
\text { based }\end{array}$ & 213 & 582 & $100 \%$ & 9 & $37 \%(33,41)$ \\
\hline Tefera et al[18] & 2018 & SNNP & $\begin{array}{l}\text { community } \\
\text { based }\end{array}$ & 295 & 484 & $89.60 \%$ & 7 & $61 \%(57,65)$ \\
\hline Fite and Haili[26] & 2019 & SNNP & $\begin{array}{l}\text { community } \\
\text { based }\end{array}$ & 130 & 173 & $100 \%$ & 4 & $75 \%(68,81)$ \\
\hline Tesfaye et al[30] & 2018 & Amhara & $\begin{array}{l}\text { community } \\
\text { based }\end{array}$ & 494 & 846 & $98.11 \%$ & 9 & $58 \%(55,62)$ \\
\hline Wado et al[73] & 2014 & Oromia & $\begin{array}{l}\text { community } \\
\text { based }\end{array}$ & 329 & 889 & $100 \%$ & 7 & $37 \%(34,40)$ \\
\hline Yismaw et al[28] & 2019 & Amhara & $\begin{array}{l}\text { community } \\
\text { based }\end{array}$ & 228 & 301 & $100 \%$ & 9 & $76 \%(71,80)$ \\
\hline Beyene et al[74] & 2013 & Afar & $\begin{array}{l}\text { community } \\
\text { based }\end{array}$ & 157 & 762 & $97.10 \%$ & 7 & $21 \%(1824)$ \\
\hline $\begin{array}{l}\text { Mebrahtom and } \\
\text { Birhane[52] }\end{array}$ & 2013 & Afar & $\begin{array}{l}\text { community } \\
\text { based }\end{array}$ & 124 & 1534 & $98.30 \%$ & 9 & $8 \%(7.0,10)$ \\
\hline Debie and Taye[35] & 2014 & Amhara & $\begin{array}{l}\text { community } \\
\text { based }\end{array}$ & 236 & 479 & $100 \%$ & 7 & $49 \%(45,54)$ \\
\hline Facha W [40] & 2015 & SNNP & $\begin{array}{l}\text { community } \\
\text { based }\end{array}$ & 112 & 210 & $100 \%$ & 8 & $53 \%(47,60)$ \\
\hline Ebrahim and Beyene[34] & 2015 & Amhara & $\begin{array}{l}\text { community } \\
\text { based }\end{array}$ & 531 & 639 & $97.60 \%$ & 9 & $83 \%(80,86)$ \\
\hline Tessema et al [47] & 2019 & $\begin{array}{l}\text { pastoral/semi- } \\
\text { pastoral }\end{array}$ & $\begin{array}{l}\text { community } \\
\text { based }\end{array}$ & 255 & 600 & $96.60 \%$ & 9 & $43 \%(39,47)$ \\
\hline Kidane et al[25] & 2019 & $\begin{array}{l}\text { pastoral/semi- } \\
\text { pastoral }\end{array}$ & $\begin{array}{l}\text { community } \\
\text { based }\end{array}$ & 256 & 600 & $97 \%$ & 9 & $43 \%(39,46)$ \\
\hline Porth et al [37] & 2019 & SNNP & $\begin{array}{l}\text { community } \\
\text { based }\end{array}$ & 174 & 232 & $100 \%$ & 6 & $75 \%(69,80)$ \\
\hline $\begin{array}{l}\text { EDHS [51] } \\
\text { EDHS [27] }\end{array}$ & $\begin{array}{l}2011 \\
2016\end{array}$ & $\begin{array}{l}\text { National } \\
\text { National }\end{array}$ & $\begin{array}{l}\text { Survey } \\
\text { Survey }\end{array}$ & $\begin{array}{l}470 \\
781\end{array}$ & $\begin{array}{l}1930 \\
2004\end{array}$ & $\begin{array}{l}97 \% \\
98 \%\end{array}$ & $\begin{array}{l}10 \\
10\end{array}$ & $\begin{array}{l}24 \%(22,26) \\
39 \%(37,41)\end{array}$ \\
\hline EDHS [45] & 2019 & National & Survey & 443 & 1026 & $99 \%$ & 10 & $43 \%(40,46)$ \\
\hline
\end{tabular}



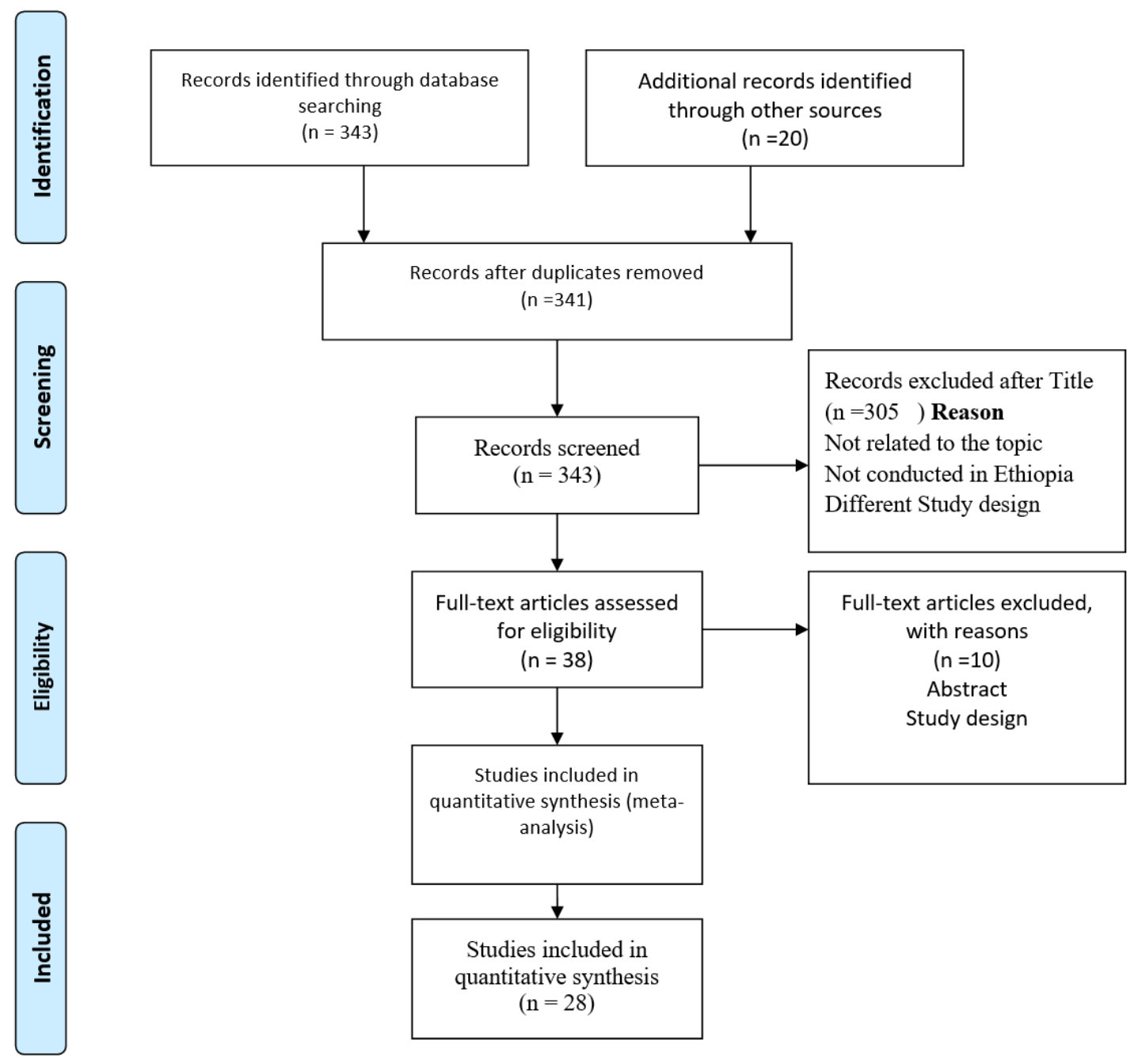

Figure 1

PRISMA Flow chart describing searching strategies of studies for systematic review and meta-analysis of immunization coverage among $12-23$ month children in Ethiopia. 


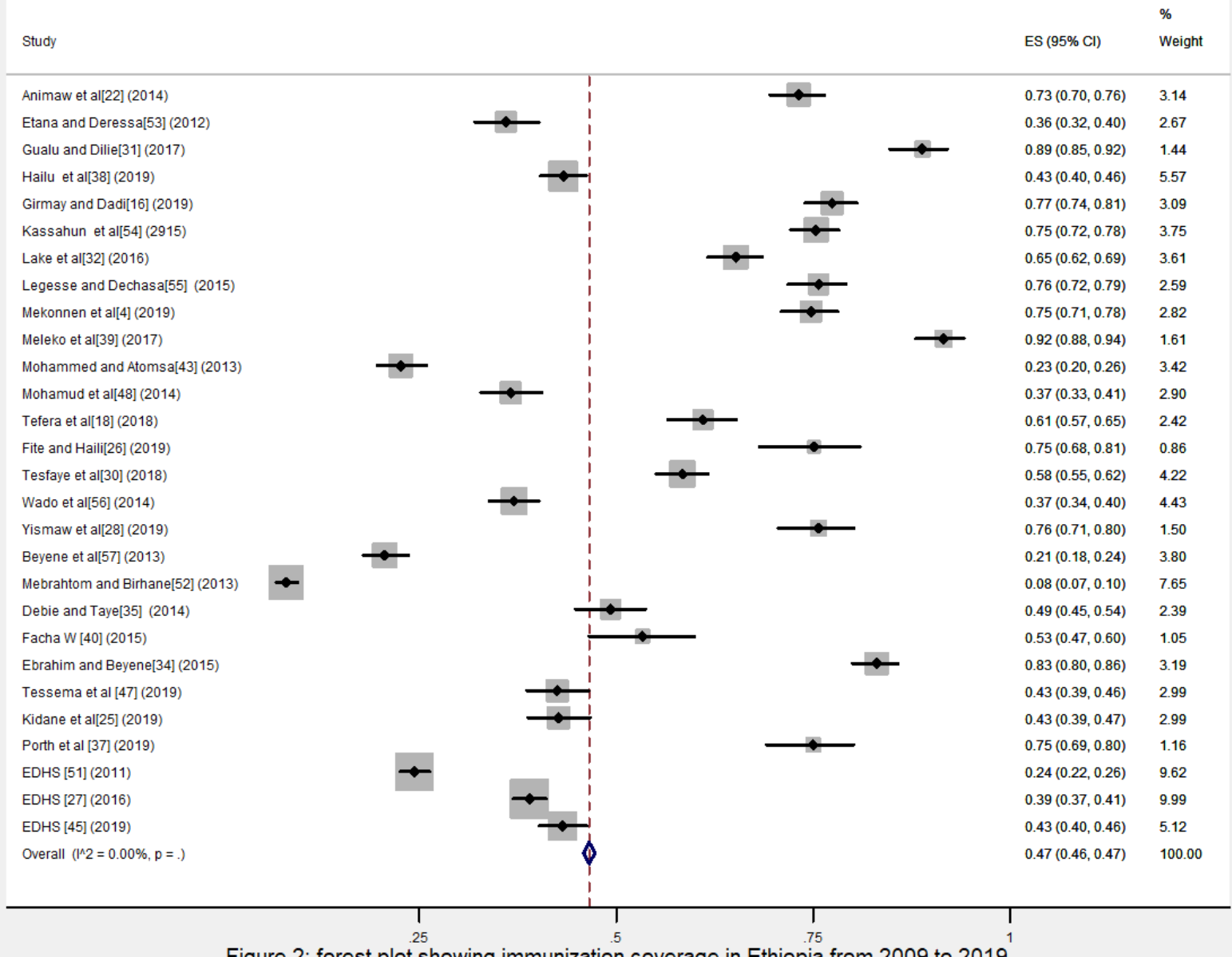

Figure.2: forest plot showing immunization coverage in Ethiopia from 2009 to 2019

\section{Figure 2}

Forest plot showing immunization coverage in Ethiopia from 2009 to 2019. 


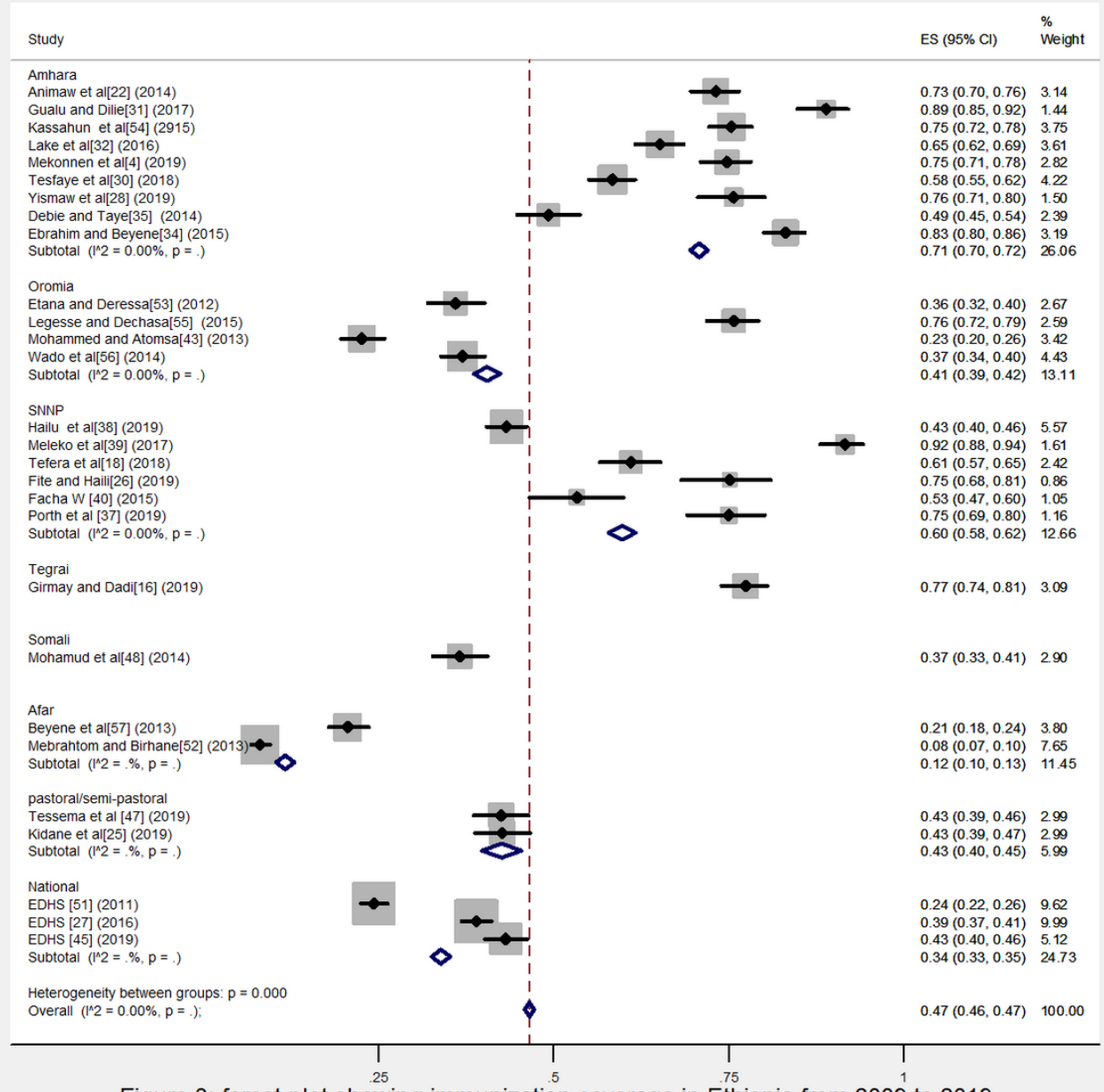

Figure.3: forest plot showing immunization coverage in Ethiopia from 2009 to 2019

\section{Figure 3}

Forest plot showing immunization coverage in Ethiopia from 2009 to 2019.

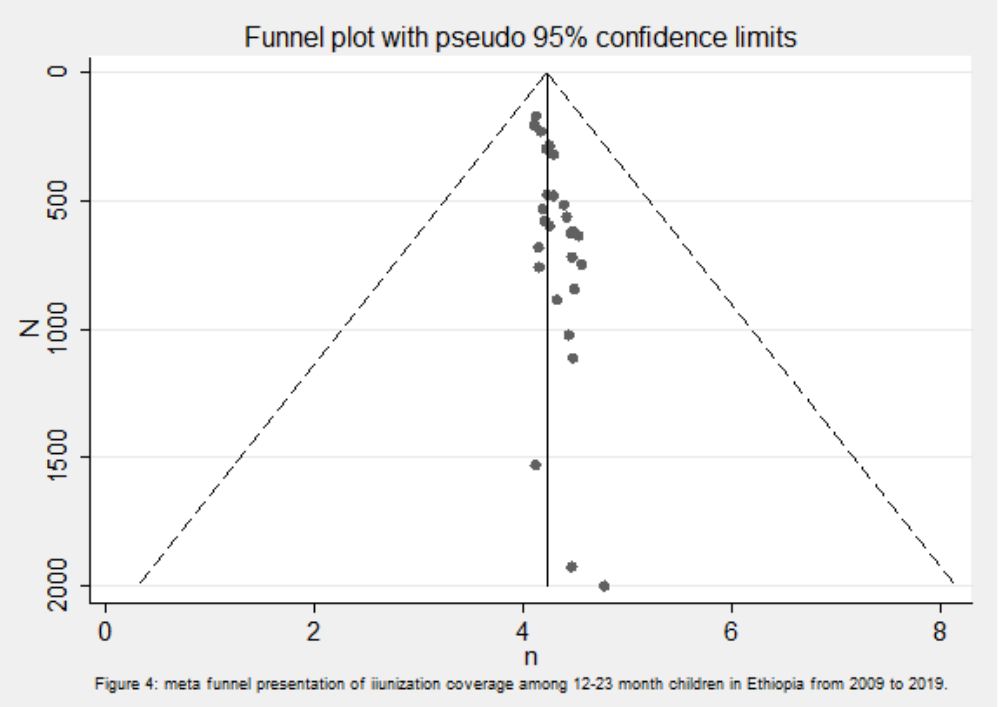

\section{Figure 4}

Meta funnel presentation if immunization coverage among 12-23 month children in Ethiopia from 2009 to 2019.

\section{Supplementary Files}


This is a list of supplementary files associated with this preprint. Click to download.

- PRISMA2009checklist.doc

Page 15/15 